\title{
Methodological notes on applying the International Classification of Functioning, Disability and Health in rehabilitation
}

\author{
Gerold STUCKI 1,2,3*, Jerome BICKENBACH 1, 2, 3, Stefano NEGRINI 4, 5
}

\begin{abstract}
${ }^{1}$ Department of Health Sciences and Health Policy, Faculty of Humanities and Social Sciences, University of Lucerne, Lucerne, Switzerland; ${ }^{2}$ Swiss Paraplegic Research (SPF), Nottwil, Switzerland; ${ }^{3}$ ICF Research Branch, a cooperation partner within the WHO Collaborating Centre for the Family of International Classifications in Germany (at DIMDI), Nottwil, Switzerland; ${ }^{2}$ Department of Clinical and Experimental Sciences, University of Brescia, Brescia, Italy; ${ }^{5}$ Don Gnocchi Foundation, Milan, Italy

*Corresponding author: Gerold Stucki, Swiss Paraplegic Research (SPF), Guido A. Zäch Strasse 4, 6207, Nottwil, Switzerland. Email: gerold.stucki@paraplegie.ch
\end{abstract}

$\mathrm{O}$ ver the last decades we have witnessed major advances in rehabilitation interventions with targets ranging from "cell to society". ${ }^{1}$ In parallel, we have seen the emergence of science-based medicine and health services research. As a consequence, we are challenged to identify, adapt or develop methodological approaches and statistical techniques suitable for research designs and analyses in clinical trials and observational studies in rehabilitation.

One could argue that this is not specific for rehabilitation, but true of any medical field. Moreover, one could claim that rehabilitation should simply adopt currently well developed and widely praised research designs, such as the randomized clinical trial and clinical cohort studies. However, research designs and the development of a solid evidence base for rehabilitation poses unique challenges. That is why a Cochrane field for rehabilitation has recently been initiated. ${ }^{2}$

At its core the methodological challenge relates to the goal of rehabilitation to optimize people's lived experience of health or functioning. ${ }^{3}$ This goal is achieved by providing the best treatment for health conditions and so developing a person's intrinsic health capacity - by strengthening a person's psychological resources, creating a facilitating physical and social environment, and finally and most importantly, by translating the po- tential from these improvements into better lived health.

With respect to outcomes we must not only study how to optimize a person's intrinsic health capacity but also how to translate this capacity into performance in interaction with the environment. Here we draw on the methodological approaches established in the social sciences as much as on the methods established in the clinical and biomedical sciences.

To foster advances in suitable research designs for rehabilitation we need a conceptual framework and ontology of domains suitable to represent the wide range of potential intervention targets and outcomes. Fortunately, with the endorsement of the World Health Organization's International Classification of Functioning, Disability and Health (ICF) ${ }^{4}$ we now have a framework and ontology we can rely on. ${ }^{3}$ Practical tools needed for the system-wide implementation of the ICF in rehabilitation science and practice ${ }^{5}$ have been developed to the point that they can be implemented as standards for the documentation of functioning. ${ }^{3}$ What is now needed is their wide-spread application and integration into scientific inquiry and day-to-day practice.

The European Journal of Physical and Rehabilitation Medicine (EJPRM) has thus decided to launch a new format referred to as "Methodological Notes on Applying the ICF in Rehabilitation". In a first series we present 


\section{COPYRIGHT ${ }^{\odot} 2017$ EDIZIONI MINERVA MEDICA}

functioning as the third health indicator complementing mortality and morbidity in the health system, and how functioning can serve as indicator across the five main health strategies and as the key indicator for rehabilitation. Next we illustrate how functioning information can be used for rehabilitation at the clinical, service and policy level of a learning health system. The third note provides practical guidance on how to document functioning following four easy to follow steps.

We hope that the notes will be useful for rehabilitation scientists when they are planning a study, conducting an analysis or preparing a publication. Finally, we see the Methodological Notes as contributions towards establishing a solid methodological foundation for the emerging Cochrane field for rehabilitation.

\section{References}

1. Stucki G, Reinhardt JD, Grimby G, Melvin J. Developing "Human Functioning and Rehabilitation Research" from the comprehensive perspective. J Rehab Medicine 2007;39:665-71.

2. Negrini S, Kiekens C, Levack W, Grubisic F, Gimigliano F, Ilieva E, et al. Cochrane physical and rehabilitation medicine:a new field to bridge between best evidence and the specific needs of our field of competence. Eur J Phys Rehabil Med 2016;52:417-8.

3. Stucki G. The Olle Hook Lectureship 2015:The World Health Organization's paradigm shift and implementation of the International Classification of Functioning, Disability and Health in rehabilitation. J Rehabil Med 2016;48:486-93.

4. World Health Organization. The International Classification of Functioning, Disability and Health. Geneva:WHO Press; 2001.

5. Stucki G, Zampolini M, Juocevicius A, Negrini S, Christodoulou N Practice, science and governance in interaction: European effort for the system-wide implementation of the International Classification of Functioning, Disability and Health (ICF) in Physical and Rehabilitation Medicine. Eur J Phys Rehabil Med 2016 [Epub ahead of print].

Conflicts of interest. - The authors certify that there is no conflict of interest with any financial organization regarding the material discussed in the manuscript. Article first published online: November 24, 2016. - Manuscript accepted: November 22, 2016. - Manuscript received: November $17,2016$.

(Cite this article as: Stucki G, Bickenbach J, Negrini S. Methodological notes on applying the International Classification of Functioning, Disability and Health in rehabilitation. Eur J Phys Rehabil Med 2017;53:132-3. DOI: 10.23736/S1973-9087.16.04571-8) 